\title{
Calibration and validation of thermal imagers
}

by G. Machin ${ }^{1}$, R. Simpson, M. Broussely

\author{
National Physical Laboratory, Temperature Measurement Group, Teddington, Middlesex, TW11 OLW, UK \\ ${ }^{1}$ Visiting Professor Universities of Glamorgan and Valladolid
}

\begin{abstract}
This paper will consider how to improve confidence in the use of thermal imagers quantitatively, that is for actual temperature measurement. The proposed route will be through the implementation of best international measurement practice via calibration, traceability and accreditation. Reference blackbody standards that have been rigorously qualified will be described, with emphasis on developments in clinical thermography.
\end{abstract}

\section{Introduction}

The practice of thermal imaging is at a crossroads. In the past, for the vast majority of applications, qualitative analysis was sufficient. However there is a growing need to have properly quantified thermal imaging. For example, if cross-centre image exchange is required to study a problem, if clinical or other decisions are made based on thermal imager temperature measurement (e.g. preventing or delaying transit through an airport) or for the construction of a database of images taken by different thermal imagers, then questions concerning normalisation and calibration need to be addressed. This brings with it a requirement of measurement rigour that has not generally been practised or appreciated.

The purpose of this paper is to outline how, through the use of appropriate and available metrology "tools", the accurate calibration of thermal imagers can be obtained. The "tools" namely calibration, [and associated uncertainty analysis] traceability and accreditation will be described in some detail. Emphasis will be given to the requirements of the international standard ISO17025 and how its implementation in the thermal imaging community, and in particular in the laboratories and manufacturers testing and supplying thermal imagers, would significantly improve the practice of accurate thermal imaging. The paper will then describe, for illustrative purposes, the facilities at the NPL for performing the traceable calibration of thermal imagers. Particular attention will be paid to developments in lower temperature medical applications, both of a variable temperature blackbody source and novel in-field fixed point blackbodies, that are used to provide in-situ image assurance for critical applications.

Finally a review of the recent proposed standard 62D_616_CDV for implementing thermal imaging in an airport/port-of-exit/port-of-entry environment will be given. This will highlight the requirement for key metrological input at the early stage of standards formulation.

\section{Assuring temperature measurements}

Proper temperature (in fact any) measurement requires the establishment of a rigorous process that enables all measurements to be traced back to a reliable national standard, which itself has been qualified internationally through top-level comparisons with standards in other national measurement institutes. From a temperature perspective the current standard is the International Temperature Scale of 1990 (ITS-90) [1]. All temperature measurements throughout the world should ultimately be traceable back to this scale. The process of ensuring that this is the case has three steps each one improving the rigour of the measurement. These steps are: calibration, traceability and accreditation.

\section{Calibration}

In order to be satisfied that a measurement device is operating satisfactorily it is important that it is periodically calibrated. In the context of a thermometer/thermal imager, calibration is the process whereby a traceable ITS-90 temperature $\left(T_{90}\right)$ is attributed to the output of a thermometer/thermal imager, in such a way that the measurement uncertainties are understood. Put another way calibration is an operation that determines the relationship between temperature values indicated by the thermometer/thermal imager and those (ITS-90) temperature values realised by the standard (in the case of a thermal imager the standard is invariably a blackbody cavity). So calibration provides information on the performance of a device, e.g. is it operating properly, does it need adjustment? To be able to perform a calibration presupposes the existence of references of known temperature. The calibration of infrared thermometers/thermal imagers at the NPL is performed using wellcharacterised, high precision blackbody standard reference sources. These are described in Section 3 and are similar to those found in other national measurement institutes around the world.

\section{Uncertainty}

In the proceeding sub-section calibration was spoken of in the following terms: "calibration is the process whereby a traceable ITS-90 temperature $\left(T_{90}\right)$ is attributed to the output of a thermometer or thermal imager, in 
such a way that the measurement uncertainties are understood". For any calibration to be valid the uncertainty in the calibration process needs to be clearly understood and quantified. There are internationally recognised ways of determining and ascribing uncertainty and these are detailed in the ISO Guide to the expression of Uncertainty in Measurement [GUM] [2]. Anyone who is interested in reliable measurements whatever the quantity will want to be well-versed in the contents of the GUM and in the formation of uncertainty budgets.

\section{Traceability}

It is possible to have a thermometer/thermal imager calibrated by a calibration laboratory and still not have a reliable calibration. This is because the calibration laboratory may not be able to rigorously demonstrate what is known as traceability for its in-house reference standards. Traceability is a very important general concept that applies to all areas of measurement. The traceability of a thermometer is derived through a demonstrable unbroken chain of measurements to a common standard (in this case the ITS-90), held by a national measurement institute (in the UK this is the NPL). Traceability can be obtained through accredited calibration laboratories, which are in turn demonstrably traceable to the local National Measurement Institute. If a thermometer is not calibrated to a traceable standard it is not measuring an internationally recognised temperature. If it is important that measurements be reliable then the calibration laboratory used will need to be able to demonstrate reliable traceability to national standards for both the quantity and also range in which one is interested.

For the user of such services, demonstrating that the calibration laboratory being used had such robust traceability would be both a time consuming and costly business. This is where the third step in the process of ensuring reliable measurements, that of accreditation, is so important. This is because it negates the need for individuals to check whether traceability, and a whole host of other issues surrounding reliable measurements such as trained staff or adequate procedures, are in place. Accreditation, when properly implemented, ensures that the user of the calibration services can be confident that the calibration laboratory can reliably perform the calibrations, in a traceable way with the uncertainty they claim.

\section{Accreditation}

This is an often neglected but vital part of the process. Accreditation is an objective means of reviewing a calibration methodology. The accreditation standard used for such an assessment is known as ISO/IEC17025:2005 "General requirements for the competence of testing and calibration laboratories" (ISO 17025") [3]. This covers, in detail, all the necessary issues required to ensure reliable traceable calibrations are performed. A third party (in the UK this is performed by the United Kingdom Accreditation Service (UKAS)) reviews and assesses against the standard the calibration providers' ability to provide reliable traceable calibrations. This would include a critical assessment of the following; the calibration procedures, uncertainty budgets, laboratory accommodation, records, equipment (including the reference standards that provide the traceable link) and competency and training of staff that carry out calibrations. When the requirements of the ISO17025 standard are met the calibration laboratory can issue certificates carrying the accreditation body's logo showing that it meets the requirements of the international standard and is performing validated traceable calibrations.

A note of warning must be sounded here, on two fronts.

- Less scrupulous calibration providers sometimes claim to be traceable to national standards. If they make such a claim then it is important to ask if they are accredited and, if not, why not?

- If such providers then say they are accredited then its necessary to ask a second question; are you accredited to ISO17025? Many laboratories and manufacturers are accredited but to manufacturing/process standards ISO9001, this is not sufficient in and of itself to guarantee reliable traceable measurements.

To summarise this section: it is clear that to perform reliable quantative (temperature) measurements the starting point must be to ensure that the equipment being used is properly calibrated. This is most easily demonstrated to yourself and to others if the thermometer/imager is calibrated traceable to national standards in a laboratory that has been third party assessed to ISO17025 and certified as competent to perform such a calibration.

\section{Reference sources for thermal imager calibration}

To ensure that thermal imagers and IR thermometers are properly calibrated, sources of known radiance are required. These are almost invariably blackbody sources. When constructing a blackbody source for such a purpose its design needs to be carefully considered to ensure that its radiance closely approximates to that of an ideal blackbody (i.e. that it is to all intents and purposes a Planckian radiator) and that the temperature sensing is performed in such a way that the temperature measured is representative of the radiance emitted. The NPL has constructed a suite of blackbody reference sources for this purpose [4] which are described briefly below.

Note that with the advent of focal plane array (FPA) imagers individual pixel gain and offsets need to be corrected for by the process of determining the "flat field" before calibration is performed. This requires a large source of uniform radiance such that the whole field is uniformly illuminated. The blackbodies described here are not immediately suitable for this purpose though such a source can be relatively easily realised. 


\section{Variable temperature blackbody sources}

The NPL has a suite of blackbody reference sources for the accurate calibration of IR thermometers and thermal imagers [4]. The characteristics of the principal blackbody cavities used for calibration of thermometers/thermal imagers are given in table 1. These are based on heat pipe technology and cover the range $-40{ }^{\circ} \mathrm{C}$ to nominally $1000^{\circ} \mathrm{C}$. Heat-pipes are utilised because they have very small temperature gradients and hence produce a quasi-isothermal enclosure, an essential prerequisite for a good blackbody. The temperature of the blackbody radiators is determined through a calibrated contact sensor traceable (except in the case of the large area sodium cavity) to a primary realisation of the ITS-90. Typical uncertainties for the blackbody sources when used for the calibration of thermometers/thermal imagers are around $0.2{ }^{\circ} \mathrm{C}(k=2)$ at ambient temperatures. All calibrations undertaken at NPL using these facilities are accredited through UKAS.

Table 1: Characteristics of NPL blackbody reference sources

\begin{tabular}{|l|l|l|l|l|l|l|}
\hline $\begin{array}{l}\text { Working } \\
\text { fluid of heat } \\
\text { pipe }\end{array}$ & $\begin{array}{l}\text { Working } \\
\text { aperture/mm }\end{array}$ & $\begin{array}{l}\text { Temperature } \\
\text { range } /{ }^{\circ} \mathrm{C}\end{array}$ & $\begin{array}{l}\text { Estimated } \\
\text { isothermal } \\
\text { emissivity }\end{array}$ & $\begin{array}{l}\text { Source } \\
\text { uncertainty } \\
(k=2) /{ }^{\circ} \mathrm{C}^{2}\end{array}$ & $\begin{array}{l}\text { Accredited } \\
\text { calibration } \\
\text { uncertainty } \\
(\mathrm{k}=2) /{ }^{\circ} \mathrm{C}\end{array}$ & $\begin{array}{l}\text { Temperature } \\
\text { sensor }\end{array}$ \\
\hline Ammonia & Max 70 & -40 to 50 & $0.999+$ & $0.04-0.07$ & 0.2 & $\mathrm{PRT}$ \\
\hline Water & 40 & 50 to 250 & 0.9997 & $0.04-0.08$ & 0.2 & $\mathrm{PRT}$ \\
\hline Caesium & 40 & 300 to 600 & 0.9994 & $0.04-0.07$ & 0.3 & $\mathrm{PRT}$ \\
\hline Sodium & 40 & 500 to 1000 & 0.9994 & 0.2 & 0.3 & $\begin{array}{l}\text { Au/Pt } \\
\text { thermocouple }\end{array}$ \\
\hline $\begin{array}{l}\text { Large area } \\
\text { sodium }\end{array}$ & 75 & 500 to 1000 & $>0.999$ & 0.4 & 0.4 & $\begin{array}{l}\text { Embedded } \\
\text { type } \\
(\mathrm{Pt} / 13 \% \mathrm{Rh})\end{array}$ \\
\hline
\end{tabular}

A schematic diagram is given in figure 1 for a typical blackbody cavity used at NPL. The heat pipe is inserted in a single zone electrically heated furnace. The blackbody target is an integral part of the heat pipe, in the form of a tube with a $120^{\circ}$ cone at the end. At high temperatures the internal cavity surface is made of oxidised inconel; at lower temperatures high emissivity is achieved through use of a high emissivity coating. The demountable temperature sensors for the ammonia, water and caesium heat pipe blackbody cavities are standard platinum resistance thermometers. These are calibrated directly to the UK's primary realisation of ITS-90 at the NPL. A high performance gold platinum thermocouple is used as the temperature sensor for the sodium heat pipe cavity and this is calibrated at a high level ISO17025 accredited laboratory. The operation of the blackbody cavity is straightforward. The furnace is heated until stable, and within the operating range of the heat pipe, and the radiance temperature is then taken to be that of the contact sensor. The ammonia heat-pipe is in a liquid thermostatted enclosure, and has the facility for a dry gas purge below the dew point, but otherwise its operation and design is similar to the other heat-pipe cavities [5]. The large area sodium heat-pipe cavity has a somewhat different design (due to its large aperture) to the other cavities in that its temperature sensor is not demountable, but instead is permanently mounted inside the heat-pipe structure. The temperature of this source is assigned through primary radiation thermometry using a high performance radiation thermometer operating at either 0.65 $\mu \mathrm{m}$ or $0.9 \mu \mathrm{m}$. The high performance radiation thermometer is calibrated directly traceable to the NPL primary gold point blackbody and its relative spectral response and linearity is known very precisely.

\footnotetext{
${ }^{1}$ This is the uncertainty of the ITS-90 radiance temperature of the source. It is considerably lower than the accredited uncertainty. The latter is larger because additional uncertainty factors need to be accounted for such as alignment of the imager and the source, the stability of the imager and additional statistical terms.

${ }^{2}$ The quoted source uncertainty is for $11 \mu \mathrm{m}$ for the ammonia and water blackbody cavities, $1.6 \mu \mathrm{m}$ for the caesium and sodium blackbody cavities and $0.9 \mu \mathrm{m}$ for the large area sodium cavity

3 The temperature sensors are PRT = platinum resistance thermometer, Au/Pt thermocouple $=a$ thermocouple whose thermoelements are made of pure gold and platinum respectively, type $\mathrm{R}$ thermocouple $=\mathrm{a}$ thermocouple whose thermoelements are made up of pure platinum and platinum alloyed with $13 \%$ rhodium
} 


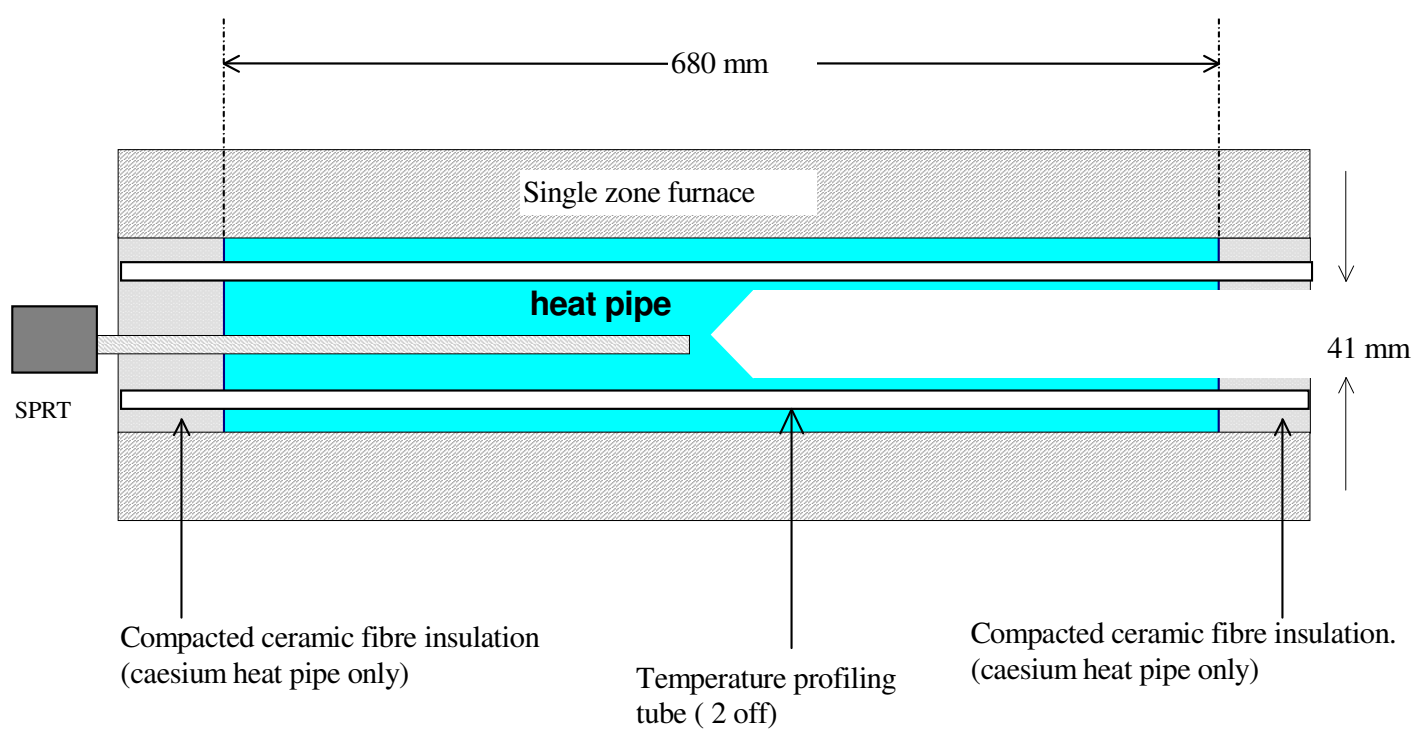

Fig 1. A schematic diagram of a blackbody reference source used at NPL

The performance of the blackbody sources of NPL has been qualified by comparison to those of other National Measurement Institutes. For example one wide ranging comparison between $156^{\circ} \mathrm{C}$ and $962^{\circ} \mathrm{C}$ including the national measurement institutes of Germany, Italy, The Netherlands, France and Spain found that the agreement of the primary scale realisations between the participants was well within the $k=2$ measurement uncertainties of the comparison [6].

\section{Variable temperature and fixed-point blackbody cavities for medical applications}

The application of thermal imaging in medicine is one where, for some applications, knowledge of the temperature, as opposed to temperature differences, is essential, for instance in the tracking of the progress of a disease/condition over time, the analysis of cross-centre images of the same condition, or the establishment of a "normals" baseline. This section of the paper describes NPL's work with clinical thermographers in the UK to help improve the practice and understanding of the background principles of thermal imaging when applied to medicine. This has taken several years of strong involvement and has had the following three components.

- A variable temperature blackbody cavity was specifically designed and constructed by NPL for clinical thermography applications. It is directly traceable to ITS-90, and has been transported to clinical centres to determine the performance of their thermal imagers [7]. Its operating range is sub-ambient to around $80^{\circ} \mathrm{C}$ with an intrinsic uncertainty of $0.03^{\circ} \mathrm{C}(k=2)$ over its range. When the source is used for calibrations this rises to $0.2^{\circ} \mathrm{C}(k=2)$ due to additional uncertainty factors becoming significant. Studies with the reference blackbody source have shown dramatic and previously unknown variation in imager performance over the temperature range of clinical interest [8].

- To obtain the ultimate in temperature performance requires that the thermal imager has a radiometric standard of traceable temperature in the image field. A range of blackbody reference sources utilizing fixed-points of Ga-Zn eutectic $\left(\sim 25^{\circ} \mathrm{C}\right), \mathrm{Ga}\left(29.7^{\circ} \mathrm{C}\right)$ and ethylene carbonate $\left(36.3^{\circ} \mathrm{C}\right)$ have been produced for this purpose. These are repeatable to $\sim 0.1^{\circ} \mathrm{C}$ and are small enough to be located in the image plane. In 2006 the performance of the sources was validated in trials in clinical centres around the UK [9].

- Temperature measurement "best practice" has been provided through a teaching module on the IR thermography in medicine course run by the University of Glamorgan [10]. The module covers the essentials of temperature measurement, temperature scales, particularly the fundamentals and establishment of ITS-90, and the issues such as calibration, uncertainties, traceability and accreditation are discussed.

\section{A variable temperature blackbody for medical applications}

To assess the performance of thermal imagers in current use in medical and research clinics in the UK a high performance variable temperature source was developed. Its specification was tailored to meet the requirements of that community identified through a survey of UK clinical thermal imaging practitioners. The operating range of the blackbody cavity was $0^{\circ} \mathrm{C}$ to $80^{\circ} \mathrm{C}$, with provision for dry gas purging below the dew point $\left(\sim 10{ }^{\circ} \mathrm{C}\right)$ to prevent condensation within the blackbody. The stability of the blackbody was within $\pm 0.02^{\circ} \mathrm{C}$ over a 
period of 1 hour and the uncertainty in its radiometric temperature over the whole range was $\pm 0.03^{\circ} \mathrm{C}$ or less. The very high performance was achieved by integrating the blackbody into a stirred liquid bath that was highly isothermal due to the vigorous stirring of liquid. The cavity had an aperture of $50 \mathrm{~mm}$ (though this could be reduced if necessary) and was designed to have a very high emissivity in excess of 0.9998 . The traceability to ITS-90 was provided through a platinum resistance thermometer calibrated against the UK primary realisation of ITS-90. Figure 2 shows a cross-sectional diagram of the whole cavity assembly.

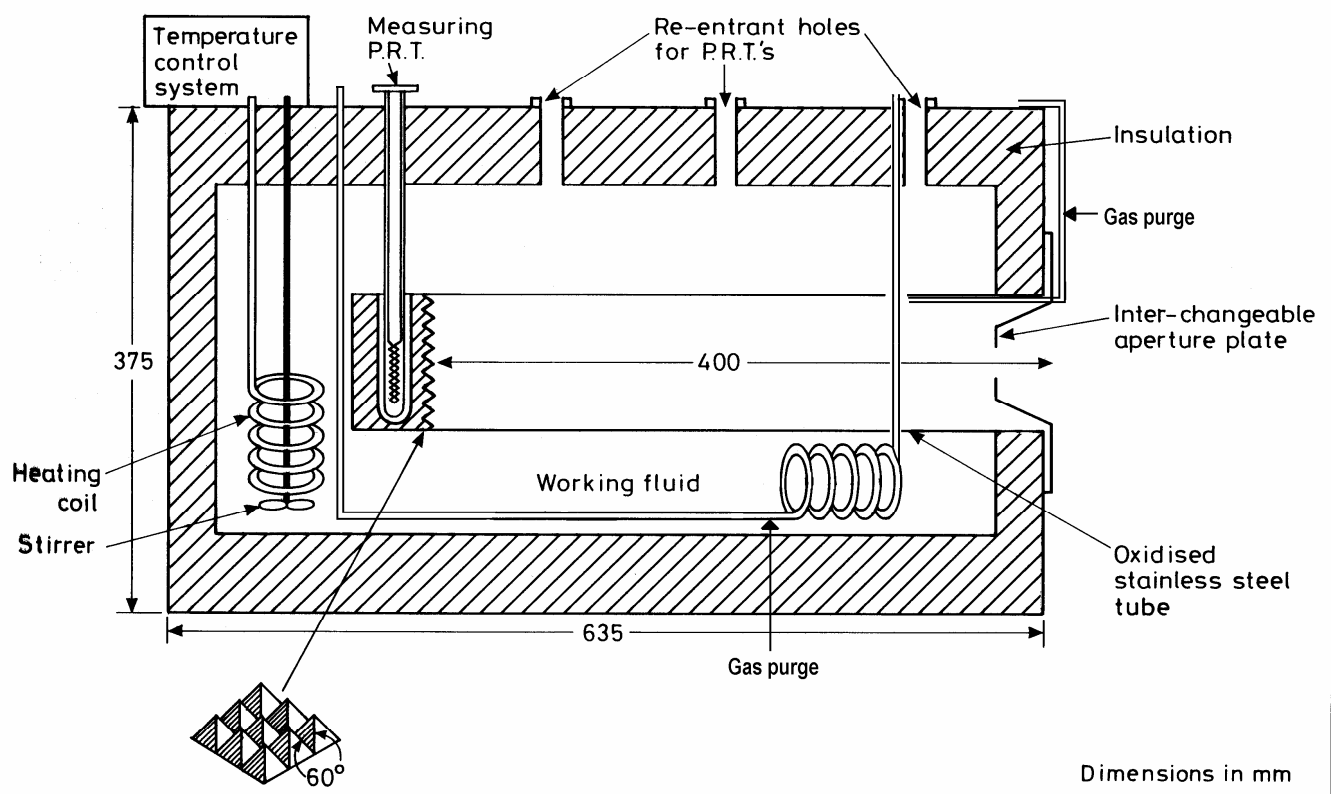

Fig 2. NPL high performance blackbody cavity designed for assessing the performance of clinical thermal imagers

This blackbody was circulated to three clinical/research centres where thermal imagers were being used for medical purposes. Five imagers underwent a set of standard tests to assess their performance. Fig. 3 shows the very striking difference that was observed in radiometric performance between the thermal imagers. Imagers $1 \mathrm{a}-\mathrm{c}$ were un-cooled focal plane array imagers in various states of calibration, imager 2 was a liquid nitrogencooled scanning device, imager 3 was an un-cooled focal plane array that hadn't been calibrated for over four years.

These results show that even if the imagers had been calibrated by the manufacturer [imager $1 \mathrm{a}$ and $1 \mathrm{c}$ had been calibrated less than two months before these tests were performed] their temperature performance could be relatively poor. This indicates that if these imagers were to be used as accurate temperature measurement thermometers then the traceability to ITS-90 at the manufacturer's calibration facility may need to be improved ${ }^{4}$. In any event these results show that any clinical user of such a device, if they require reliable temperature measurement, should ensure that their imager has been properly calibrated in an accredited laboratory. More worryingly it might indicate that the imagers (at least the ones tested) were not really capable of precise temperature performance, and if this was required for the clinical procedures or tests then a precision blackbody reference source would have to be available for routine performance checking in the clinic. A detailed description of the tests performed, the procedures and precautions followed and the results such as time to warm up and short-term stability can be found in $[8,11]$.

4 This may be why many thermal imager manufacturers give rather wide tolerance on radiometric temperature accuracy, up to $\pm 2 \%$ 


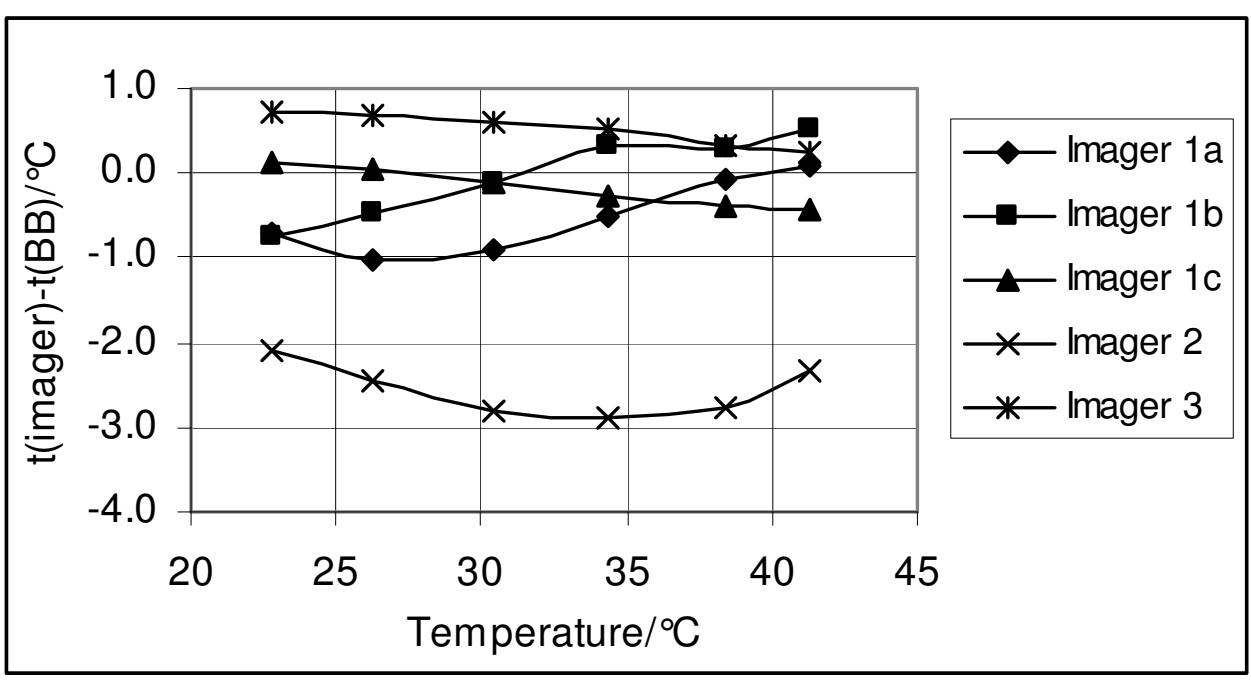

Fig 3. The temperature reading of a selection of clinical thermal imagers when viewing the blackbody reference source of known traceable temperature

\section{Fixed-point blackbody reference sources for in-image performance validation}

In the light of the findings of the study reported in section 3.2.1 it was clear that to obtain the best radiometric temperature performance from a thermal imager ultra-high performance blackbody reference sources, traceable to ITS-90, yet small enough to be placed in the image during measurement, were necessary. This method has been used in a limited way by some manufacturers, particularly during the avian flu/SARS epidemic to confirm the in-situ performance of imagers at airports [e.g. 12]. In those cases a small blackbody source was used whose temperature was determined by a contact thermometer. Although certainly better than no reference source, the blackbody used, because it relied on a contact thermometer, could be prone to long term drift and would need regular recalibration to maintain performance and in particular traceability to ITS-90. A more radical approach was followed in the developments reported here [9]. Instead of relying on a contact thermometer sensor to provide traceability to ITS-90, the blackbody sources constructed were based upon fixed-point materials. A fixed-point is based on the phase transition of a material: generally either a melting or freezing point. Whilst the phase change is underway the temperature of the material does not change as it takes in latent heat during melting or releases latent heat during freezing. These sources admittedly are more difficult to use than a simple electrically operated blackbody, but have the advantage of being driftless and failsafe (they either won't work or should always give the right temperature ${ }^{5}$ ) in operation. Figure 4 shows a typical melt curve of one of the fixedpoints, in this case the Ga-Zn eutectic.

The blackbody cavities were constructed from Teflon. Each had an aperture of $26 \mathrm{~mm}$ and were designed to have an isothermal emissivity of 0.9983 . The blackbody cavities were inserted into a Teflon crucible that held the fixed-point material, and sealed so as to prevent leaks of the material and to facilitate sterilization of the fixedpoints themselves, if required. The three fixed-point materials that were used as temperature references were Ga$\mathrm{Zn}$ eutectic $\left(25.3^{\circ} \mathrm{C}\right)$, pure $\mathrm{Ga}\left(29.8^{\circ} \mathrm{C}\right)$ and an organic material ethylene carbonate $\left(35.9^{\circ} \mathrm{C}\right)$. The latter temperature was a little lower than the published value of $36.3^{\circ} \mathrm{C}$, and this was probably due to some residual impurities and/or dissolved gas in the base material. However, despite that, the radiometric performance of the ethylene carbonate fixed-point was unimpaired. The usefulness of these fixed points is immediately apparent as they spanned the temperature range of most ordinary clinical procedures. Each cavity required a particular initiation procedure (reported in [9]) but the performance was similar and flat melting and freezing plateaux (within $0.1^{\circ} \mathrm{C}$ ) of $1-3$ hours duration were obtained. The assigned radiometric temperature uncertainty of each fixed-point was $\pm 0.4^{\circ} \mathrm{C}(k=2)$, but this could, with care, be improved. Figure 5 shows the fixed-points in use in a clinical centre.

These fixed points have been used successfully in trials in the UK in medical centres as a means of confirming and providing traceable radiometric temperatures. It is envisaged that the final uncertainty of the sources could be around $\pm 0.2^{\circ} \mathrm{C}(k=2)$. If these types of measures were implemented widely in the clinical thermal imaging community then questions concerning the performance of the imagers could be unequivocally answered and reliable traceability with uncertainties in temperatures of $<1^{\circ} \mathrm{C}$ could potentially be obtained.

5 The only exception to this is in the unlikely event of the fixed-point material becoming significantly contaminated during use. 


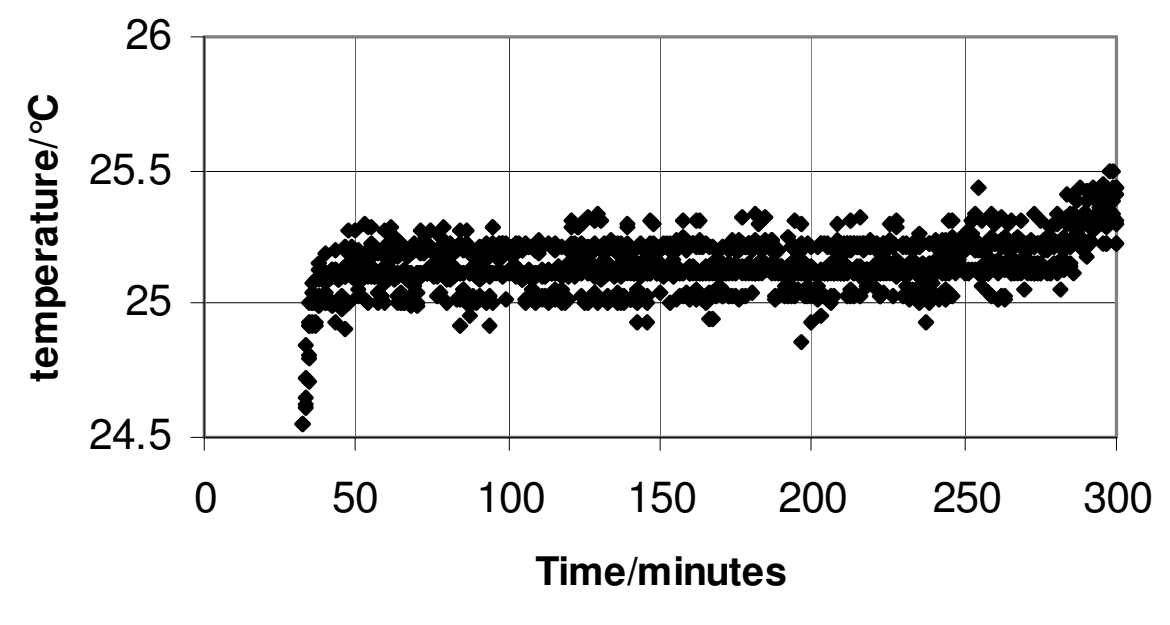

Fig 4. A typical melting curve of Ga-Zn eutectic, the digitisation (at $0.1^{\circ} \mathrm{C}$ ) of the radiation thermometer used to assess the radiometric performance of the fixed point is evident
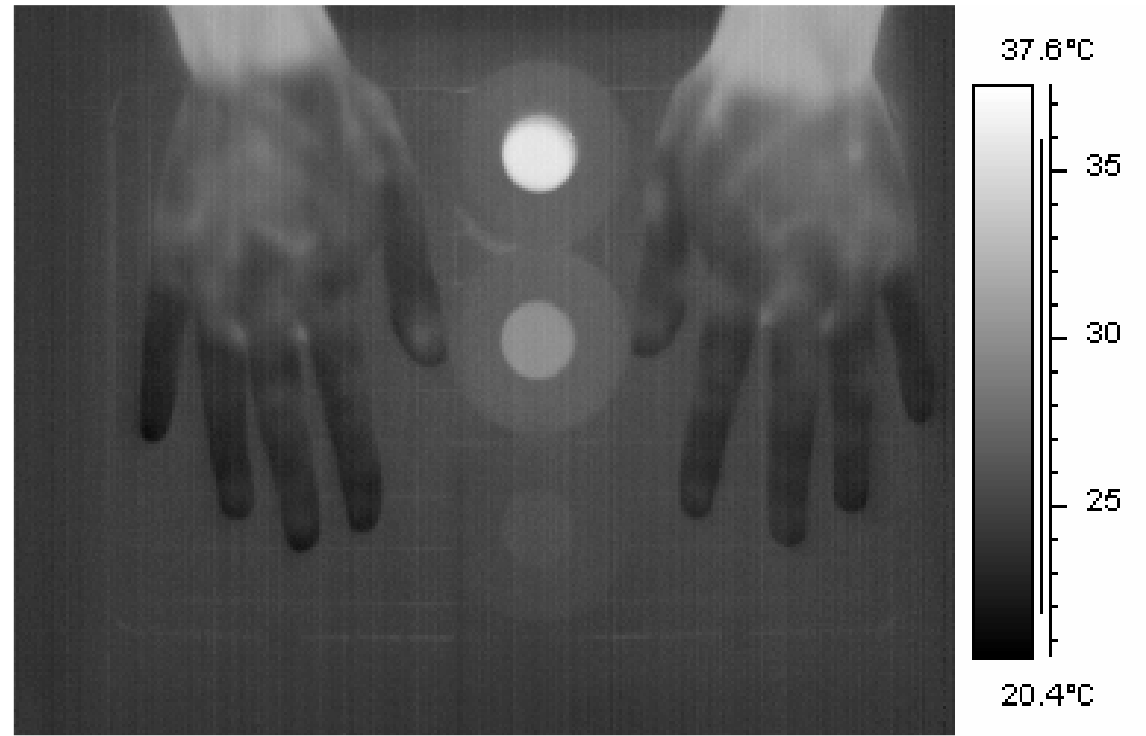

Fig 5. The three NPL fixed point blackbody cavities. From the top of the image, ethylene carbonate, gallium and gallium-zinc eutectic for in-image radiometric temperature validation

\section{Provision of basic training in temperature measurement}

The development of basic metrology tools like those described above has provided established clinical thermal imaging practitioners the means to obtain, if so desired, reliable traceable temperatures. However there is a need for new entries into the field to be provided with some training on simple temperature measurement principles and practice. This need was met by adding a module on temperature measurement to the already well established "Thermal Imaging In Medicine Course" run from the University of Glamorgan [10]. In that module all the issues covered in this paper are explained. In particular the fundamentals of temperature, especially the background to ITS-90 is covered. This is particularly necessary as the temperature aspects of thermal imaging are often taken for granted when in reality there are many technical issues that need to be carefully weighed even before the temperature reading an imager gives can be relied upon.

\section{Proposed standard for thermal imaging at airports and other points of entry/exit}

Standards and standardisation bodies have a powerful role to play in ensuring that good measurement practice is followed and implemented. This can be seen in the development of a standard for identifying febrile individuals at ports of entry and exit.

The advent of SARS and avian flu have given rise to concerns about a possible global pandemic. It was recognised that thermal imaging has a significant role to play in the containment of any such outbreak. Through using thermal imaging at, in particular, airports, febrile individuals could be identified and isolated until further 
tests could be undertaken to confirm or otherwise their infectious status (i.e. whether they genuinely have a fever).

Work is underway to develop an ISO standard, building upon an earlier standard written by the Singapore authorities $[13,14]$ to be used to develop systems for identifying febrile individuals using thermal imaging [15]. One particular feature of this standard is the involvement of metrologists during its development this has lead to appropriate and realistic metrology being promulgated, negating unrealistic expectations which were a feature of early implementation of thermal imaging during the SARS outbreak.

\section{Summary}

This paper has summarised how to attain reliable temperature measurements, traceable to ITS-90 using thermal imaging. The metrology "tools" of calibration (with rigorous uncertainty analysis), traceability and accreditation have been described and these are the foundation to ensuring good measurement practice is followed.

The thermal imaging calibration capabilities at the UK national measurement institute (NPL) have been described.

A case study is given of how the metrology tools combined with appropriate levels of training has been used by the UK medical thermography community to improve the quality of temperature measurements.

Finally the role of standards in promulgating good measurement practice in thermal imaging was described through the case study of identifying febrile individuals to minimise the spread of infections.

\section{REFERENCES}

[1] H., Preston-Thomas, "The International Temperature Scale of 1990", Metrologia, 27, 1990, pp3-10 and p. 107

[2] International Organization for Standardization, "Guide to the Expression of Uncertainty in Measurement," 1993.

[3] BS EN ISO/IEC17025: 2005 "General Requirements for the competence of testing and calibration laboratories".

[4] G. Machin, B. Chu, "High quality blackbody sources for infra-red thermometry and thermography between $-40^{\circ} \mathrm{C}$ and $1000{ }^{\circ} \mathrm{C}$ ", Imaging Science, 48, 2000, p.15-22

[5] B. Chu, G. Machin, "A low temperature blackbody reference source to $-40^{\circ} \mathrm{C}$ ", Meas. Sci. Technol. 10 , 1999, 1-6

[6] M. Battuello, F. Girard, T. Ricolfi, M. Sadli, P. Ridoux, O. Enouf, J. Perez, V. Chimenti, T. Weckstrom, O. Struss, E. Filipe, N. Machado, E. van der Ham, G. Machin, H. McEvoy, B. Gutschwager, J. Fischer, V. Schmidt, S. Clausen, J. Ivarsson, S. Ugur, A. Diril, "The European project TRIRAT; Arrangements for Results of the comparison of local temperature scales with transfer infrared thermometers between $150{ }^{\circ} \mathrm{C}$ and $962{ }^{\circ} \mathrm{C}$ " In Proceedings of Temperature its Measurement and Control in Science and Industry, Vol. 7, ed. Ripple D., AIP Conference Proceedings, Chicago, 2003, pp 903-908

[7] R. Simpson, G. Machin, H.C. McEvoy, R.L. Rusby, "Traceability and calibration in Temperature Measurement: A clinical necessity", J Med. Eng. \& Technol. 30, 2006, 212-217

[8] R. Simpson, P. Plassman, K. Howell, P. Campbell, Investigation of thermal imager performance quantitative medical thermography, In preparation, 2008

[9] R. Simpson, H.C. McEvoy, G. Machin, K. Howell, M. Naeem, P. Plassmann, F. Ring, P. Campbell, C. Song, J. Tavener, I. Ridley, "In field-of-view thermal image calibration system for medical thermography applications", To be published in the International Journal of Thermophysics, 2008

[10] http://www.comp.glam.ac.uk/pages/staff/pplassma/Medlmaging/Events/IRCourse8/index.html

[11] R. C. Simpson, "IR thermometry standards for medicine", PhD University of Glamorgan, to be submitted, 2008

[12] http://www.landinst.com/infrared/products/thermal_imaging/body_imager.htm

[13] Technical reference for thermal imagers for human temperature screening: part1: Requirements and test methods TR 15, Part 1, 2003, Spring, Singapore, ISBN 9971-67-963-9

[14] Technical reference for thermal imagers for human temperature screening: part 2: Implementation guidelines TR 15, Part 2, 2004, Spring, Singapore, ISBN 9971-67-977-9

[15] ISO/IEC 60601-2-59/CDV "Particular requirements for basic safety and essential performance of screening thermographs for human febrile temperature screening 